\title{
An Investigation into Creep Cavity Development in 316H Stainless Steel
}

\author{
Hedieh Jazaeri ${ }^{1, *(0)}$, P. John Bouchard ${ }^{1}$, Michael T. Hutchings ${ }^{1}$, Mike W. Spindler ${ }^{2}$, \\ Abdullah A. Mamun ${ }^{1,3}$ and Richard K. Heenan ${ }^{4} \mathbb{D}$ \\ 1 Department of Engineering and Innovation, The Open University, Walton Hall, Milton Keynes MK7 6AA, \\ UK; john.bouchard@open.ac.uk (P.J.B.); michael.hutchings@open.ac.uk (M.T.H.); \\ abdullah.mamun@bristol.ac.uk (A.A.M.) \\ 2 Assessment Technology Group, EDF Energy Nuclear Generation Ltd., Barnett Way, Barnwood GL4 3RS, UK; \\ mike.spindler@edf-energy.com \\ 3 Department of Mechanical Engineering, University of Bristol, Bristol BS8 1TR, UK \\ 4 ISIS Facility, STFC Rutherford Appleton Laboratory, Didcot OX11 0QX, UK; richard.heenan@stfc.ac.uk \\ * Correspondence: hedieh.jazaeri@open.ac.uk; Tel.: +44-1908-653897
}

Received: 1 February 2019; Accepted: 6 March 2019; Published: 12 March 2019

\begin{abstract}
Creep-induced cavitation is an important failure mechanism in steel components operating at high temperature. Robust techniques are required to observe and quantify creep cavitation. In this paper, the use of two complementary analysis techniques: small-angle neutron scattering (SANS), and quantitative metallography, using scanning electron microscopy (SEM), is reported. The development of creep cavities that is accumulated under uniaxial load has been studied as a function of creep strain and life fraction, by carrying out interrupted tests on two sets of creep test specimens that are prepared from a Type-316H austenitic stainless steel reactor component. In order to examine the effects of pre-strain on creep damage formation, one set of specimens was subjected to a plastic pre-strain of $8 \%$, and the other set had no pre-strain. Each set of specimens was subjected to different loading and temperature conditions, representative of those of current and future power plant operation. Cavities of up to $300 \mathrm{~nm}$ in size are quantified by using SANS, and their size distribution, as a function of determined creep strain. Cavitation increases significantly as creep strain increases throughout creep life. These results are confirmed by quantitative metallography analysis.
\end{abstract}

Keywords: creep damage; cavitation; small angle neutron scattering; scanning electron microscopy; austenitic stainless steel

\section{Introduction}

Creep cavitation [1] is an important failure mechanism in steel components operating at high temperature. The role of cavities in limiting the creep life of materials was first reported by Greenwood [2,3]. Since then much research has been conducted in this area; however, the mechanisms of cavity nucleation are still not completely understood [1], particularly in engineering alloys with complex secondary particles [4]. Although creep cavitation is often associated with the final stage of creep deformation, it actually nucleates at a relatively early stage of creep. The minimum stable nucleation size of creep cavity is not well-established, but theoretical work has indicated it to be in the range of 2-5 nm [5]. Nucleation usually occurs at the grain boundaries that are oriented normal to the principal stress direction, with the number of cavities per unit grain boundary that are approximately proportional to the creep strain [6-8]. However, cavities can also nucleate within the grains, particularly under higher applied stresses. The cavities gradually grow in size during deformation [9], as well as new cavities nucleating continuously during the entire creep life. 
Classical cavitation theories associate cavity nucleation with high stress concentration at grain boundary ledges, triple junctions, and particles $[10,11]$. These models usually invoke the concept of a threshold stress, below which the cavity nucleation rate is negligible for practical purposes and above which the rate of nucleation is so rapid that cavities nucleate at all available sites over a short period of time. However, these models fail to capture experimental observations; such as extensive cavity nucleation during creep deformation under a much lower applied stress than the theoretical threshold stress that is predicted by these models. This discrepancy has led to the development of other cavity nucleation models based upon grain boundary sliding [12], and interactions of dislocation sub-structures with grain boundaries [13]. These models have been supported by experimental observations of creep cavitation, using various microscope-based techniques (such as Optical, Scanning Electron Microscopy (SEM), and Transmission Electron Microscopy (TEM)) [7,14-18]. Whilst these techniques can provide important information regarding the location, extent, and morphology of creep cavities, it is difficult to infer the distribution of sub-micron-sized cavities in a representative volume of the material. The latter is required to elucidate cavity nucleation and growth mechanisms in complex engineering alloys, and to understand the effects of microstructural evolution and prior deformation.

In principle, it is possible to use small-angle neutron scattering (SANS) to measure cavities in a size range of 10 to $1000 \mathrm{~nm}$ in a macroscopic volume (several cubic millimeters) of material, depending on the instrument used [19]. Traditional metallographic techniques are destructive, time consuming, two-dimensional, operator-dependent, and are often best suited for studying larger cavities [20]. In contrast, SANS can provide relatively quick, non-destructive volumetric measurement of cavities in cubic millimeter-sized samples of material. Together with complementary quantitative metallography, it has been previously used to measure creep-induced cavities in Type $316 \mathrm{H}$ stainless steel samples taken directly from power plant weldments that have exhibited cracking [17,18]. SANS can also provide quantitative volumetric measures of the size and growth evolution of creep cavities that depend upon the applied stress and temperature environment [21].

In this paper, an investigation into creep-induced cavity development in Type $316 \mathrm{H}$ austenitic steel under two different conditions of stress and temperature is reported. The conditions chosen are representative of those experienced in current and future power plant operations. One set of creep specimens was plastically pre-strained before creep deformation, in order to investigate plasticity-driven cavity nucleation, while the other set was deformed under creep loading conditions. The plastically pre-strained samples represent the as-manufactured condition of many components entering high-temperature power plant operation, including welded joints [22]. The magnitude and sign of plastic pre-strain can influence the minimum creep rate, strain-to-failure, and the rupture life [23]. SANS experimental work is presented by measuring creep cavitation as a function of creep strain in each of the two sets of creep specimens (where each specimen was interrupted at increasing levels of creep strain). Complementary measurements of cavitation using SEM quantitative metallography are also reported. The broader object of the study is to improve the current state of understanding of the mechanisms of cavity nucleation and growth in Type $316 \mathrm{H}$ stainless steel, and to help formulate new physically-based cavitation damage models.

\section{The Specimens Examined}

Two sets of specimens, creep-deformed under the two different conditions of pre-strain, stress, and temperature were examined in this study. The loadings of each specimen were carried out in accordance with BS EN ISO 204:2009. The specimens were extracted from a 316H stainless steel forged cylinder after long-service in a UK Advanced Gas Cooled Reactor nuclear power plant. This material has a grain size of $88 \pm 9 \mu \mathrm{m}$, measured by the mean linear intercept method, a room temperature $0.2 \%$ proof stress of $285 \mathrm{MPa}$ with the chemical composition presented in Table 1 [24]. This material had been removed from service after approximately $91,000 \mathrm{~h}$ exposure to temperatures of up to about $520^{\circ} \mathrm{C}$, following the discovery of reheat cracking near to cylinder to the nozzle weld. Due to the material's long exposure in service, extensive inter- and intragranular precipitation was observed from optical 
microscopy analysis. The observed precipitates are mainly $\mathrm{M}_{23} \mathrm{C}_{6}$ carbides [24]. The distribution of the intragranular precipitates were inhomogeneous among different grains. The observed intragranular precipitates were mostly of circular morphology, while the intergranular precipitates were relatively large, with high aspect ratios. Hong et al. [25] has reported the observation of similar morphology of precipitates in aged 316 stainless steel.

Table 1. Chemical composition (weight \%) of the specimens.

\begin{tabular}{cccccccccc}
\hline $\mathbf{C}$ & $\mathbf{S i}$ & $\mathbf{M n}$ & $\mathbf{P}$ & $\mathbf{S}$ & $\mathbf{C r}$ & $\mathbf{N i}$ & $\mathbf{M o}$ & $\mathbf{A l}$ & $\mathbf{C u}$ \\
\hline 0.066 & 0.42 & 1.00 & 0.029 & 0.015 & 17.82 & 11.18 & 2.33 & 0.003 & 0.23 \\
\hline $\mathbf{S n}$ & $\mathbf{V}$ & $\mathbf{W}$ & $\mathbf{C o}$ & $\mathbf{P b}$ & $\mathbf{B}$ & $\mathbf{N}$ & $\mathbf{N b}$ & $\mathbf{T i}$ & $\mathbf{F e}$ \\
\hline 0.016 & 0.031 & 0.068 & 0.093 & 0.003 & 0.0051 & 0.096 & 0.007 & 0.004 & Bal. \\
\hline
\end{tabular}

The geometry of the creep specimen used for the creep test is shown in Figure 1. In the first set of tests, a total of six specimens were used. Each specimen was subjected to an $\sim 8 \%$ tensile plastic pre-strain at room temperature, followed by uniaxial creep deformation at $550{ }^{\circ} \mathrm{C}$ under $320 \mathrm{MPa}$ start-of-test engineering stress. A temperature of $550{ }^{\circ} \mathrm{C}$ was selected to correspond with the maximum service temperature that is experienced by $316 \mathrm{H}$ stainless steel within UK nuclear power plants. The $0.2 \%$ yield stress of this material at $550{ }^{\circ} \mathrm{C}$ was measured to be $185 \mathrm{MPa}$. Wilshire et al. [23] reported that in the absence of recrystallization, room temperature pre-straining of $316 \mathrm{H}$ stainless steel modifies the creep property values, but only when the pre-strain treatment exceeds the plastic component of the initial specimen extension on loading at the creep temperature. The application of a $320 \mathrm{MPa}$ stress at $550{ }^{\circ} \mathrm{C}$ was found to introduce a $\sim 7.2 \%$ instantaneous plastic strain in the material. Therefore, a higher pre-strain of $8 \%$ was chosen, such that after pre-straining, the application of the initial stress $(320 \mathrm{MPa})$ at $550{ }^{\circ} \mathrm{C}$ for the creep test would introduce a negligible inelastic instantaneous strain. This was to ensure that the creep cavity nucleation mechanism in this set of samples would be influenced by a controlled level of plastic pre-strain. The small instantaneous elastic strain upon the application of load was excluded from the total creep strain reported here.

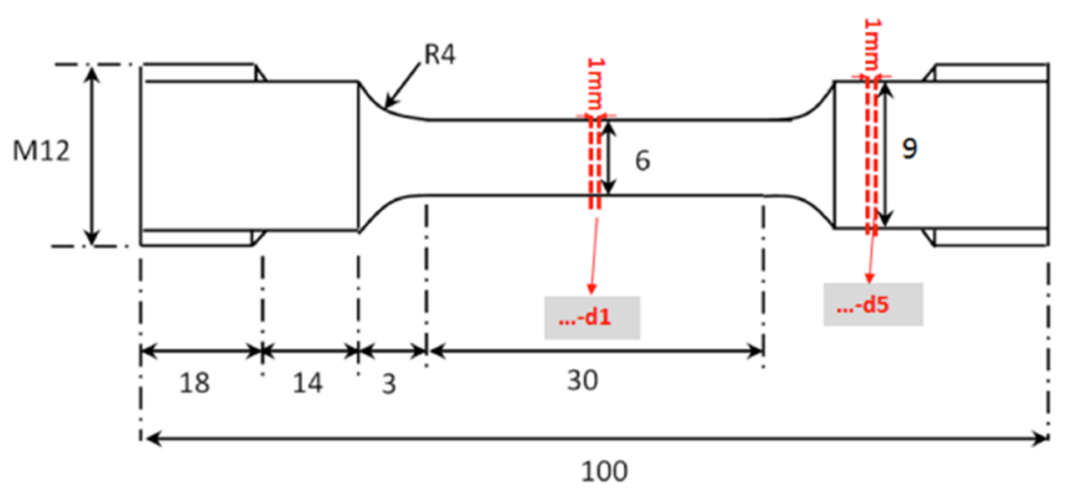

Figure 1. The creep specimen geometry in $\mathrm{mm}$. The position of the disc samples, $\mathrm{d} 1$ and $\mathrm{d} 5$, removed from each interrupted creep test specimen, and used for the measurements are marked.

In the second set of tests, a total of four specimens were used. Each specimen was subjected to uniaxial creep deformation at $675^{\circ} \mathrm{C}$ under $150 \mathrm{MPa}$ start of test engineering stress. The aim was to trigger cavity nucleation under pure creep conditions. The $0.2 \%$ yield stress of this material at $675^{\circ} \mathrm{C}$ was measured to be $165 \mathrm{MPa}$. Negligible instantaneous plastic strain was measured upon initial loading to $150 \mathrm{MPa}$ for the creep tests. As for the first set, small instantaneous strains were excluded from the strain data analysis. The test temperature of $675^{\circ} \mathrm{C}$ was selected, in order to accelerate the creep tests at an applied stress that is sufficiently low, to ensure that the initial plastic loading strain 
was negligible, whilst the material substructures and work-hardening behaviors are similar to those at $550{ }^{\circ} \mathrm{C}[24]$.

In each set of specimens the loading was interrupted at different stages of creep life, up to rupture, covering primary, secondary, and tertiary regimes [24]. The creep strain measured at each stage of the two loading conditions is shown in Figure 2, and summarized in Table 2.
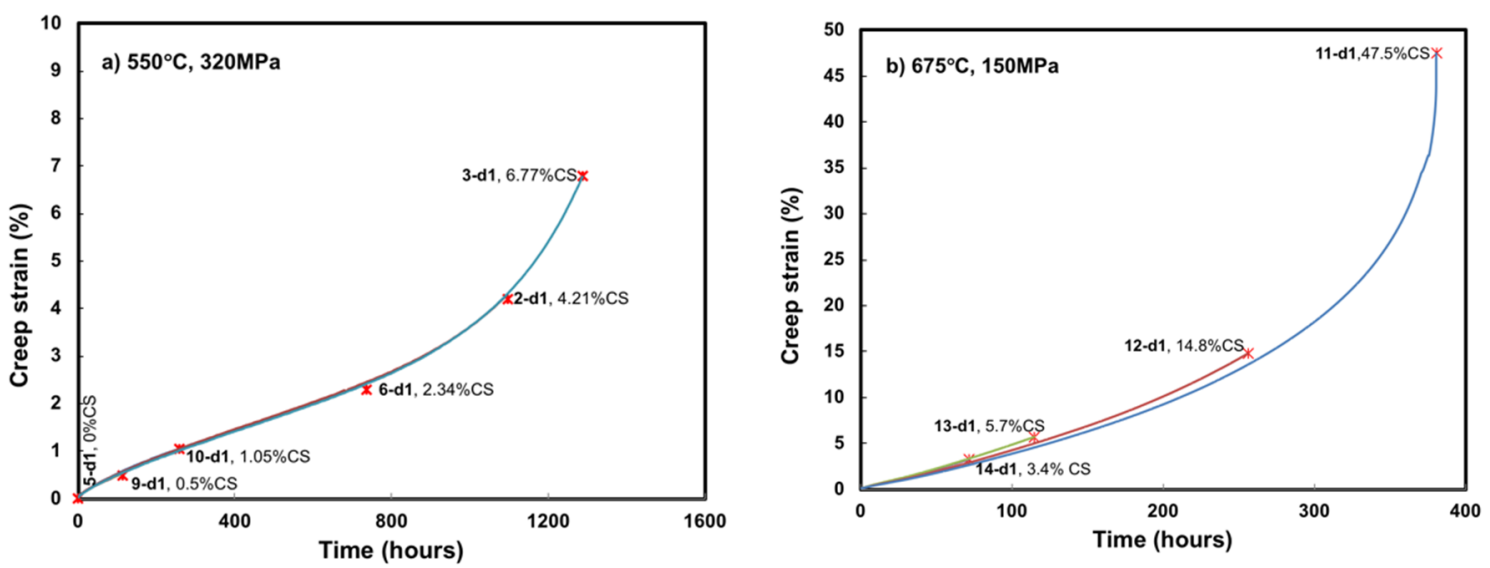

Figure 2. Creep curves for creep test conditions of: (a) $550{ }^{\circ} \mathrm{C}$ under $320 \mathrm{MPa}$ (after $8 \%$ pre-strain); and (b) $675^{\circ} \mathrm{C}$ under $150 \mathrm{MPa}$. The creep interruption points have been labelled with the sample ID and $\%$ of creep strain (CS) on each curve.

Table 2. The interrupted creep test specimen ID, and strain experienced by each, under the two creep test conditions. The specimen ID is that used for creep test specimens; the sample ID is that used for the discs cut from the creep test specimen.

\begin{tabular}{cccc}
\hline Creep Test Condition & Specimen ID & Sample ID & Creep Strain, CS (\%) \\
\hline & HRA1C-5 & $5-\mathrm{d} 1$ & 0 \\
& HRA1C-9 & $9-\mathrm{d} 1$ & 0.54 \\
& HRA1C-10 & $10-\mathrm{d} 1$ & 1.05 \\
At $550{ }^{\circ} \mathrm{C}, 320 \mathrm{MPa}$ & HRA1C-4 & $4-\mathrm{d} 1$ & 1.4 \\
$($ after $8 \%$ pre-strain) & HRA1C-6 & $6-\mathrm{d} 1$ & 2.34 \\
& HRA1C-2 & $2-\mathrm{d} 1$ & 4.21 \\
& HRA1C-3 & $3-\mathrm{d} 1$ & 3.3 \\
& HRA1C-14 & $14-\mathrm{d} 1$ & 5.7 \\
At $675{ }^{\circ} \mathrm{C}, 150 \mathrm{MPa}$ & HRA1C-13 & $13-\mathrm{d} 1$ & 14.8 \\
& HRA1C-12 & $12-\mathrm{d} 1$ & 47.5 (Ruptured, $\left.t_{r}=381 \mathrm{~h}\right)$ \\
\hline
\end{tabular}

\section{Analysis Techniques}

Two analysis techniques were used in this study, SANS and quantitative metallography (QM) using a Zeiss Supra 55VP Field Emission Gun (FEG) scanning electron microscope (ZEISS, Germany), the details of which are described below. Two $1 \mathrm{~mm}$-thick disc samples were extracted from each interrupted test specimen at the positions shown in Figure 1. Samples of $6 \mathrm{~mm}$ diameter, marked as -d1, were extracted from the mid-length positions of each creep specimen, and of $9 \mathrm{~mm}$ diameter, marked as -d5, extracted from near the end of each creep specimen, outside but near to the grip. Separate samples were prepared for each analysis technique. The samples from the two sets of creep specimens are summarized in Table 2. These have pre-numbers; for example, 5 -d 1 , associated with creep specimens, which were originally designated by HRA1C, followed by the number. So, for example the samples, 5-d1 and 5-d5 were taken from specimen HRA1C-5. 


\subsection{Small-Angle Neutron Scattering}

The SANS measurements were carried out on the SANS2D small-angle scattering instrument at the ISIS Pulsed Neutron Source at the Rutherford Appleton Laboratory, Didcot, UK [26]. A scattering vector, $Q$, ranging from 0.0015 to $0.11 \AA^{-1}\left(0.015\right.$ to $\left.1.1 \mathrm{~nm}^{-1}\right)$ was achieved, utilizing an incident wavelength range of 4.2 to $12.5 \AA$ ( 0.42 to $1.25 \mathrm{~nm}$ ), and an instrument set up of incident and scattered flight paths of $12 \mathrm{~m}$. Two position sensitive detectors were used; the furthest, at $12 \mathrm{~m}$ from the sample, was of $1 \mathrm{~m}^{2}$ area, and its center was offset vertically by $150 \mathrm{~mm}$ and horizontally by 200 $\mathrm{mm}$. With this set up, scattering from inhomogeneities in a matrix, such as carbides and cavities, of size up to about $3000 \AA$ ( $300 \mathrm{~nm})$ can be measured. The upper limit on size is governed by the minimum value of the scattering vector, $Q$, available on the instrument, which gives a cut-off on the size distribution measured. Each disc sample examined was carefully positioned at the center of the incident beam, and the scattering measured from a circular gauge area of $4 \mathrm{~mm}$ diameter, corresponding to a volume of $\sim 12.5 \mathrm{~mm}^{3}$, at its center. The acquisition time for measurement on each disc was about $60 \mathrm{~min}$. The neutron transmission of each disc was also measured in order to enable absorption corrections to be made. Each raw scattering data set was corrected for the detector efficiencies, sample transmission, and empty beam scattering to give the cross-section using the instrument-specific software [27]. The macroscopic cross section, in $\mathrm{cm}^{-1}$, from each disc as a function of scattering vector was placed on an absolute scale using the scattering from a standard sample, a solid blend of hydrogenous and perdeuterated polystyrene, in accordance with established procedures [28].

The general analysis of SANS data is discussed by Hutchings and Windsor [29]. SANS measures an inverse transform of the defect size distribution in real space. Ideally, one might carry out this inverse transformation to obtain a size distribution, but this was simply not possible without ideal counting statistics and a complete range of all of the scattering vectors $Q$. In this study, in order to interpret the measured cross-section over the fully measured range of $Q$ for each disc, the computer routine MAXE was used, which uses the maximum entropy algorithm. The advantage of this approach is that it obviates the need to assume any prior model of the size distribution of inhomogeneous scatterers, and it covers the full range of measured wave vector, in contrast to the Guinier or Porod approaches, which cover a limited range of $Q$. The technique is a means of carrying out the inverse transform of the SANS intensity with good statistical credibility. The MAXE routine was originally developed at Southampton University and Harwell [30], and written for a mainframe computer in FORTRAN code. It has been modified to work on a PC, and recently reprogrammed in $\mathrm{C}^{++}$at the Open University with more convenient inputs and outputs. The version used, MAXE V4 (2015), was written by Mike J.H. Fox for the Mathematics, Computing and Technology Department at the Open University. A detailed description of the use of the program, which is unchanged in principle from the original, has been reported elsewhere [31]. In the analysis, a simplified model of a size distribution of spherical defects of diameter $D$ is assumed. This is the best model for giving an approximation to a sample of a steel, with a complex distribution of precipitates and cavities of different shapes and orientations. It should be noted that the matrix and defects have no magnetic scattering.

The most probable fractional volume distribution $C(D)$ for defects, where $C(D) \delta D$ gives the volume fraction of defects with diameters in the range $D$ to $D+\delta D$, is determined using the maximum entropy algorithm. This algorithm is known to give the best result for determining $C(D)$, making no prior assumptions regarding its form. In order to obtain an absolute distribution, $C(D)$, the scattering contrast factor for each defect: carbide; cavity etc., must be determined. This requires the nature of each defect to be identified which often entails the use of complementary techniques. In the present case, electron microscopy was essential to determine their nature.

The absolute macroscopic scattering cross-section, and the resulting size distribution of defects such as carbides, in the material taken from the same reactor component from which the creep test specimens reported here were fabricated, has been previously measured. It was measured on a section of material from positions where no cavitation was expected. The cross-section and size distribution from such a 'far-field' region, has been reported by Jazaeri et al. [32]. It was used as the 
cavity-free reference for the present analysis. Ideally, the scattering cross sections for such a 'far-field' reference position should be subtracted from that for each measured disc, in order to determine the scattering from creep-induced cavities. However, it was found that the resulting statistical uncertainty from the counting times used gave relatively large uncertainties in the resulting size distributions from the MAXE analysis method. The MAXE analysis method was therefore used to give a defect distribution, which we term the 'relative' size distribution, $V(D)$, from each set of scattering data separately, using a contrast factor of unity. A typical fit to the macroscopic cross section over the full $Q$ range measured from sample 3-d1 is shown in Figure 3. The fit is good over most of the cross-sectional range of four orders of magnitude, but it falls just within the larger uncertainties at the highest $Q$. The resulting 'relative' defect distribution from the 'far-field' reference position was then subtracted from that for each disc, to isolate the size distribution from any cavities which might have developed. The absolute defect size distribution $C(D)$ is then determined by dividing by the contrast factor for the assumed nature of the defects in the present case for the cavities. The contrast factor involves the difference in scattering length density between the matrix and the inhomogeneity. For cavities, it is particularly strong as the open cavities have zero scattering length density. This approach was used to determine the size distribution of the cavities in each disc sample, arising from the stage of creep deformation listed in Table 2. It should be noted that it assumes, reasonably, that the 'far field' reference scattering is appropriate to all of the disc samples.

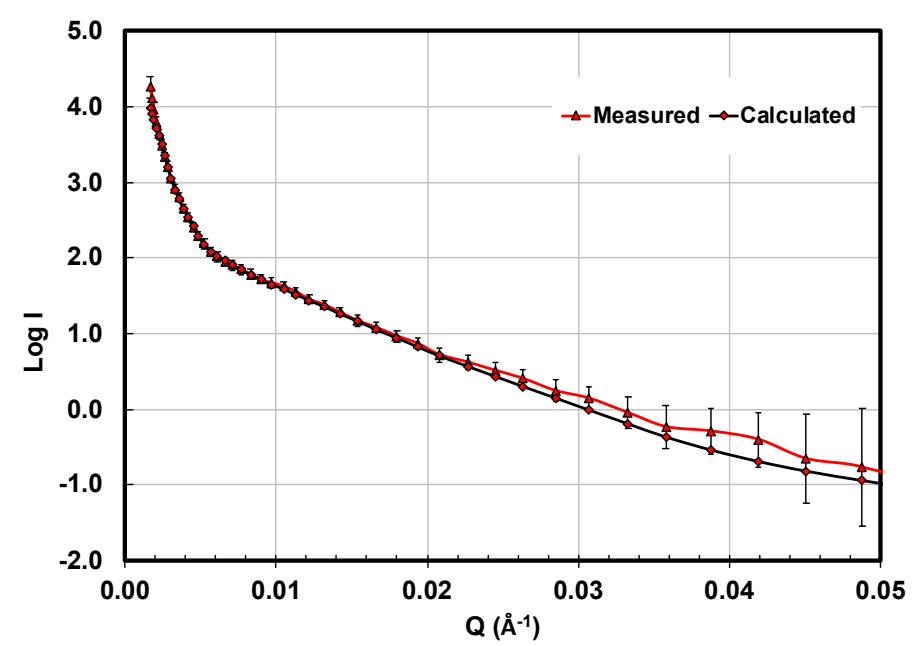

Figure 3. Variation of $\log _{10}$ of the measured absolute macroscopic cross-section, $I$, in $\mathrm{cm}^{-1}$, with wave vector $Q$ in inverse angstroms (triangles) for sample 3-d1. The calculated curve (diamonds) is the result of the MAXE fit to these data. $1 \AA^{-1}=10 \mathrm{~nm}^{-1}$.

\subsection{Quantitative Metallography}

Discs taken from each creep test sample were mounted in conductive Bakelite, in order to prepare them for examination by quantitative metallography. The preparation procedure included grinding with $\mathrm{SiC}$ papers (down to 4000 grit size) and polishing them down to $0.25 \mu \mathrm{m}$ level with diamond suspension. The final preparatory stage involved an etching procedure, where samples were immersed in Murakami's reagent $\left(10 \mathrm{~g} \mathrm{~K} \mathrm{~K}_{3} \mathrm{Fe}(\mathrm{CN})_{6}, 10 \mathrm{~g} \mathrm{KOH}, 100 \mathrm{~mL}\right.$ water) for $60 \mathrm{~s}$. Murakami's reagent was found to be the optimum solution for the sample preparation of ex-service $316 \mathrm{H}$ austenitic stainless steel material, as it highlights the grain boundary carbides without having a significant impact on the grain boundaries themselves [17]. A Zeiss Supra 55VP FEGSEM instrument was used to examine the samples in both backscattered (BS) and secondary (SE) imaging mode, using an accelerating voltage of $5-10 \mathrm{kV}$, and an aperture size of $30 \mu \mathrm{m}$. Further details of the measurement technique are given in Section 4.2 below. 


\section{Results}

\subsection{Small-Angle Neutron Scattering}

The best estimate, given by the MAXE analysis, of the fractional size distribution of cavities, $C(D)$, measured in the $6 \mathrm{~mm}$ diameter discs taken from the mid-length of the creep test specimens, under both sets of creep test conditions of stress and temperature, are presented in Figure 4. For both cases, it was seen that there are essentially two cavity size distributions. The first, with cavities of up to about $100 \mathrm{~nm}$ in diameter is more sharply peaked, and the other broader distribution spans the size range 100-300 $\mathrm{nm}$. It should be noted that the minimum scattering vector available on SANS2D cuts off the distribution above $300 \mathrm{~nm}$, so that there is no information on cavities that are larger than $300 \mathrm{~nm}$. There is a clear systematic increase in the fractional size distribution of cavities, with an increase in creep strain for the population of smaller cavities of diameters of less than $100 \mathrm{~nm}$, whereas the variation in the size distribution for the larger cavities is less pronounced, especially for the samples that are subjected to a temperature of $550{ }^{\circ} \mathrm{C}$ and a stress of $320 \mathrm{MPa}$.
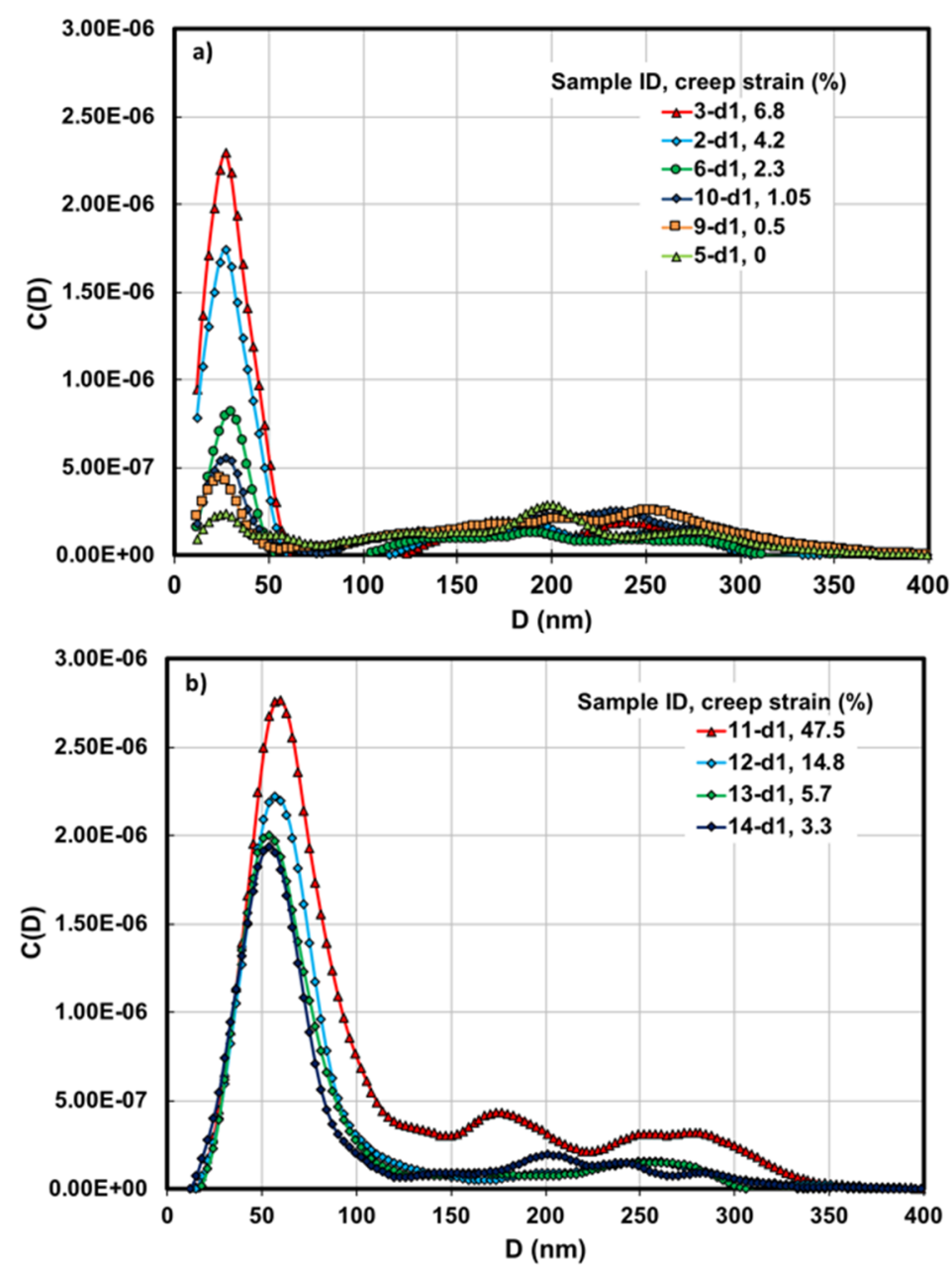

Figure 4. Small-angle neutron scattering (SANS) results, showing the increase in fractional size distribution, $C(D)$, of cavities through creep life at (a) $550{ }^{\circ} \mathrm{C}$ under $320 \mathrm{MPa}$ (after $8 \%$ pre-strain); and at (b) $675^{\circ} \mathrm{C}$ under $150 \mathrm{MPa}$.

In order to best represent the size distribution $C(D)$ for the smaller cavities, this has been fitted by a Gaussian function, as shown in Figure 5. The fitted function gives, for each strain level, a mean diameter of the smaller cavities, the peak value of $C(D)$, and the value of $C(D)$ integrated over the peak. An estimate of the corresponding values for the broader distribution between diameters of $\sim 100$ to 
$300 \mathrm{~nm}$ was calculated by a method of moments and direct summation. In fitting to the lower peak for the distributions from all samples, the fitted size range was taken up to $75 \mathrm{~nm}$. For the broader peaks calculations, the ranges for the calculations for the samples tested at $550{ }^{\circ} \mathrm{C}$ and $320 \mathrm{MPa}$ were taken to range from 75 to $300 \mathrm{~nm}$, and from 110 to $300 \mathrm{~nm}$ for the samples tested at $675^{\circ} \mathrm{C}$ and $150 \mathrm{MPa}$.

The mean diameter of these two peaks in the distribution of cavities, as a function of creep strain, is shown in Figure 6. Here the abscissa is the creep strain at each stage, expressed as a fraction of that measured closest to failure $\left(\varepsilon / \varepsilon_{f}\right)$.
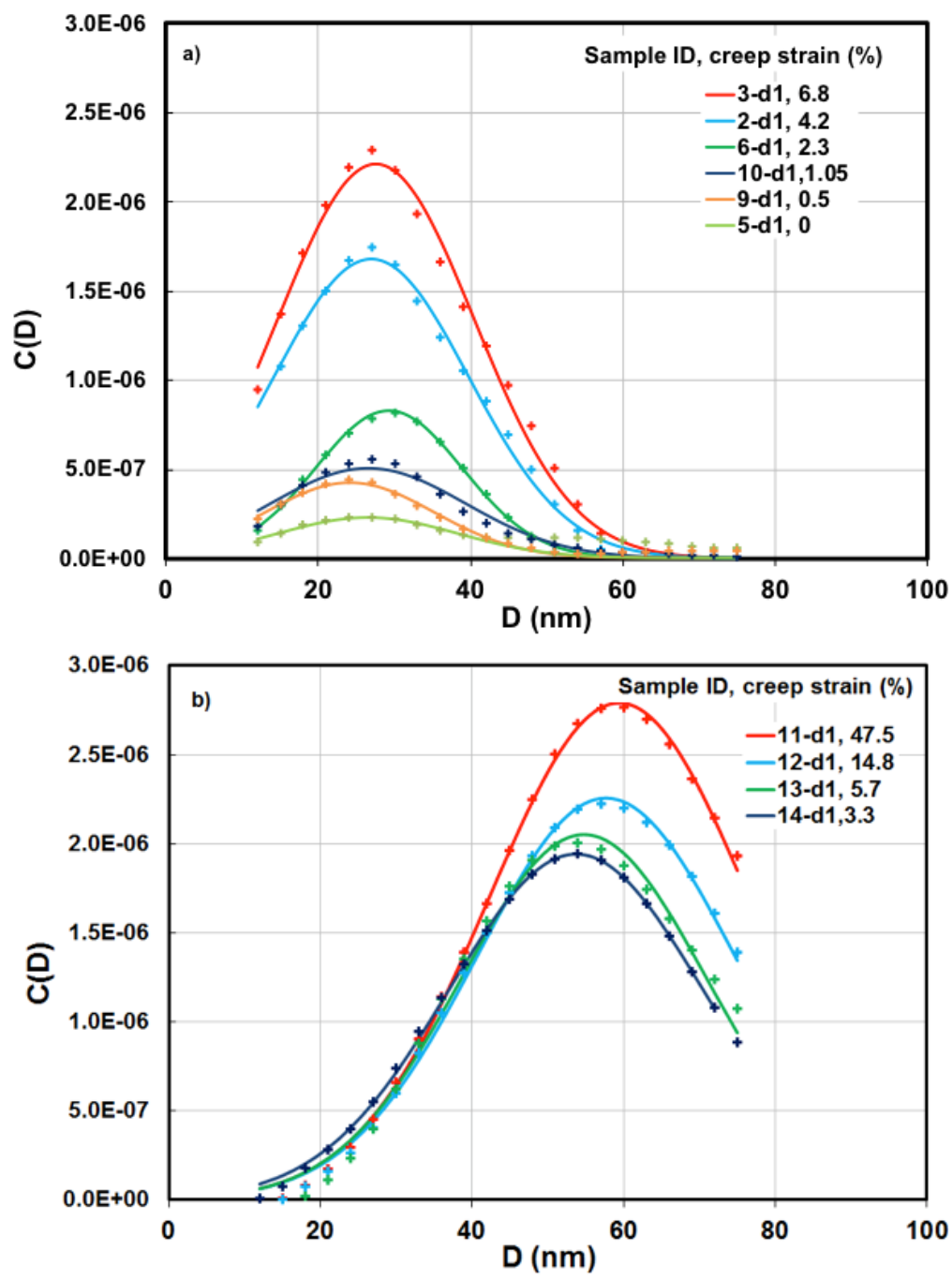

Figure 5. Gaussian functions (lines) that give the best fits to the lower peak in the distribution $C(D)$ determined from MAXE (points). Distribution from samples tested at (a) $550{ }^{\circ} \mathrm{C}$ with an applied stress of $320 \mathrm{MPa}$ (after $8 \%$ pre-strain); and (b) $675^{\circ} \mathrm{C}$ with an applied stress of $150 \mathrm{MPa}$.

The number density $N_{d}(D)$ of defects with diameters in the range $\mathrm{D}$ to $\mathrm{D}+\delta \mathrm{D}$, can be calculated from the relation:

$$
N_{d}(D)=C(D) / V_{s p h}(D),
$$

where $V_{s p h}(D)\left(=\pi D^{3} / 6\right)$ is the volume, and $N_{d}(D)$ is the number density of a spherical defect of diameter $D$. In order to estimate the number density of cavities in the diameter range of each peak in the size distribution, the integral over $C(D)$ in each peak has been determined, and the mean diameter of the corresponding peak, shown in Figure 6, used in the above equation. This is clearly an approximation, but the broader peak in the distribution gives a comparable result to a summation over the individual $N_{d}(D)$ calculated at each diameter. The results are presented as a function of $\varepsilon / \varepsilon_{f}$ 
in Figure 7. It is seen that, generally, the population of smaller cavities has a higher number density compared with the population of larger cavities. Also, it is seen that the number density of the smaller cavities, less than $75 \mathrm{~nm}$ in size, increases significantly with life fraction, for the samples which have undergone creep at $550{ }^{\circ} \mathrm{C}$ and $320 \mathrm{MPa}$. In contrast, the number density of cavities of less than $110 \mathrm{~nm}$ diameter remains relatively constant over the life-to-rupture, for the samples tested at $675{ }^{\circ} \mathrm{C}$ and $150 \mathrm{MPa}$, whereas the larger-sized cavity population $(110$ to $300 \mathrm{~nm}$ ) increases slightly in size with creep.

It is interesting to compare the data from the measurements on the discs of different diameters, $\mathrm{d} 1$ and $\mathrm{d} 5$, extracted from different parts of each creep test specimen. These specimens were subjected to different stress levels that were inversely proportional to their area at constant temperature. That is: $320 \mathrm{MPa}$ compared with $142 \mathrm{MPa}$ at $550{ }^{\circ} \mathrm{C}$, and $150 \mathrm{MPa}$ compared with $67 \mathrm{MPa}$ at $675^{\circ} \mathrm{C}$. Figure 8 shows the 'relative' size distribution, $V(D)$, for the two samples from HRA1C-3, that is 3-d1 and 3-d5, and that for the far-field position. It is clear that there are far fewer defects of size less than $50 \mathrm{~nm}$ in size in disc 3-d5, compared with disc 3-d1, and as expected there are far fewer defects in the far field region across most of the size range measured. The difference in distribution of the smaller defects between samples $\mathrm{d} 1$ and $\mathrm{d} 5$ can be attributed unambiguously to cavity formation arising from the difference in applied stress during creep.
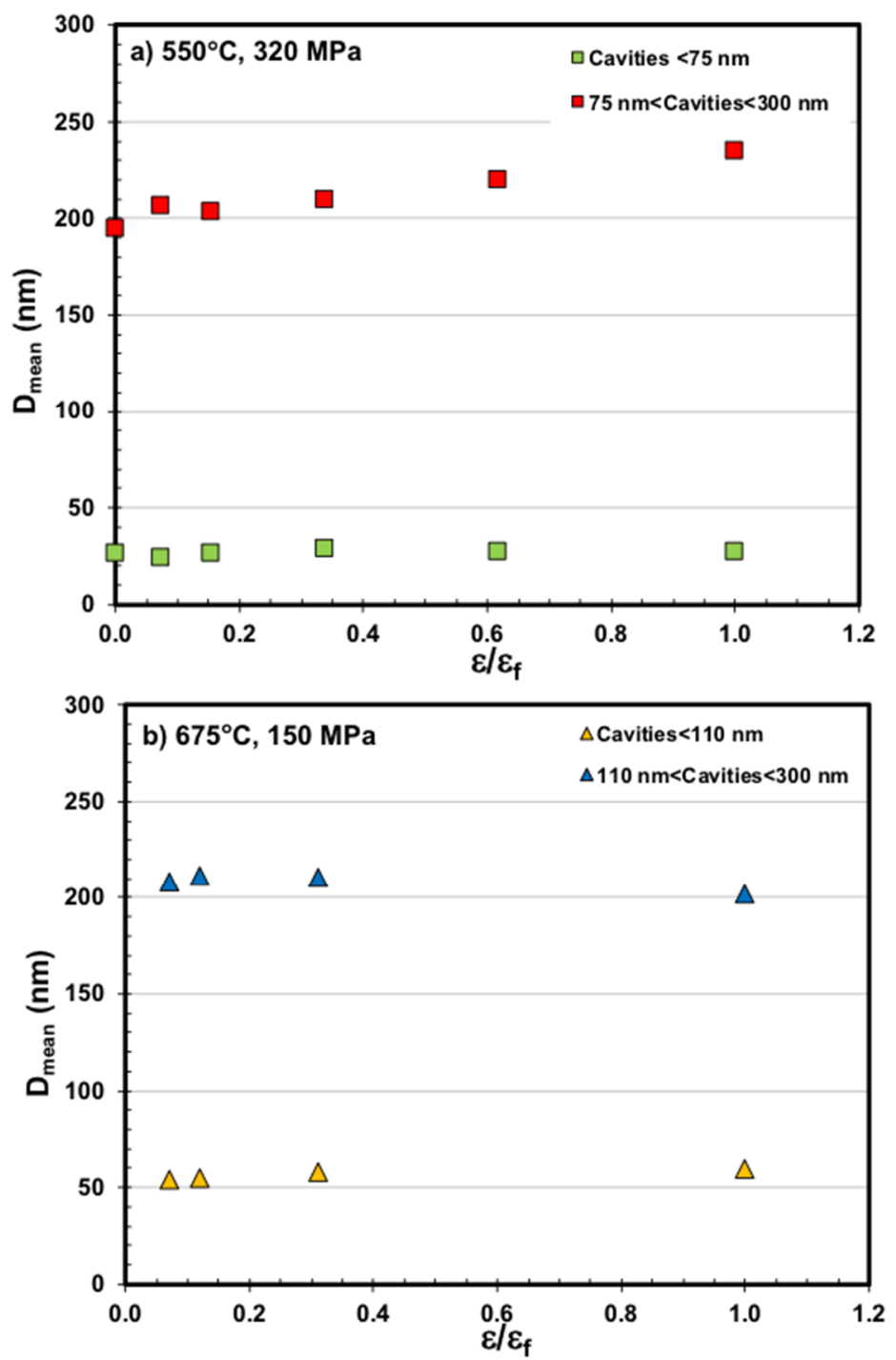

Figure 6. The mean cavity diameter, $D_{\text {mean }}$, of two populations of cavities as a function of $\varepsilon / \varepsilon_{f}$, measured by SANS: (a) $550{ }^{\circ} \mathrm{C}$ under $320 \mathrm{MPa}$ (after $8 \%$ pre-strain); and (b) $675^{\circ} \mathrm{C}$ under $150 \mathrm{MPa}$. 

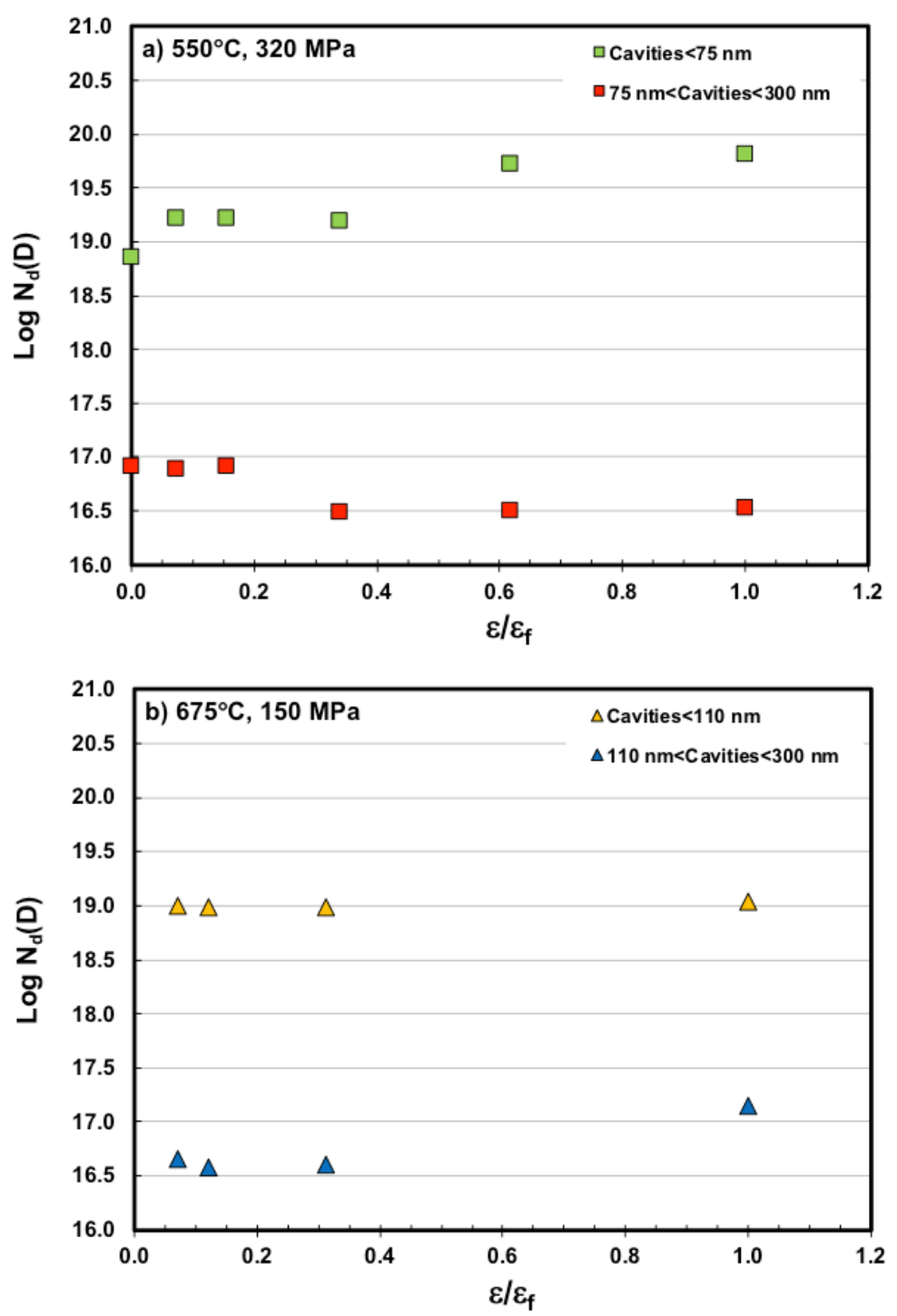

Figure 7. The number density of two populations of cavities as a function of $\varepsilon / \varepsilon_{f}$, measured by SANS. (a) $550{ }^{\circ} \mathrm{C}$ with an applied stress of $320 \mathrm{MPa}$ (after $8 \%$ pre-strain); (b) $675^{\circ} \mathrm{C}$ with an applied stress of $150 \mathrm{MPa}$.

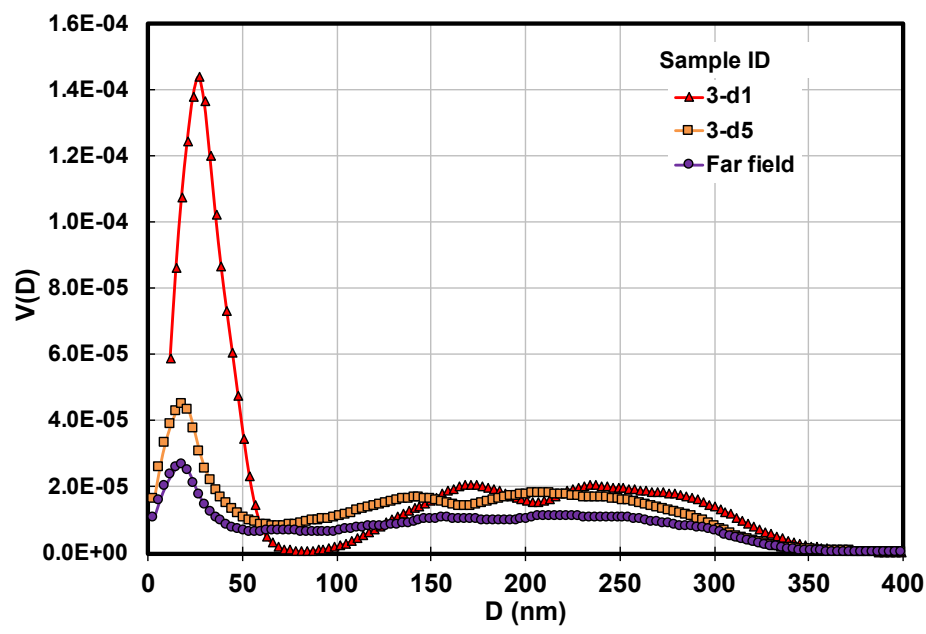

Figure 8. The "relative" size distribution, $V(D)$, of defects in sample 3-d1, from the mid position, 3-d5, from the end position of the specimen and the 'far field' reference is also shown. 
By the subtraction of $V(D)$ for the $\mathrm{d} 5$ samples from that of the $\mathrm{d} 1$ samples, and using the contrast factor for cavities, the change in size distribution of cavities, $C(D)$, as a result of the difference in applied stress alone, can be determined. These are shown for the two sets of creep conditions in Figure 9.
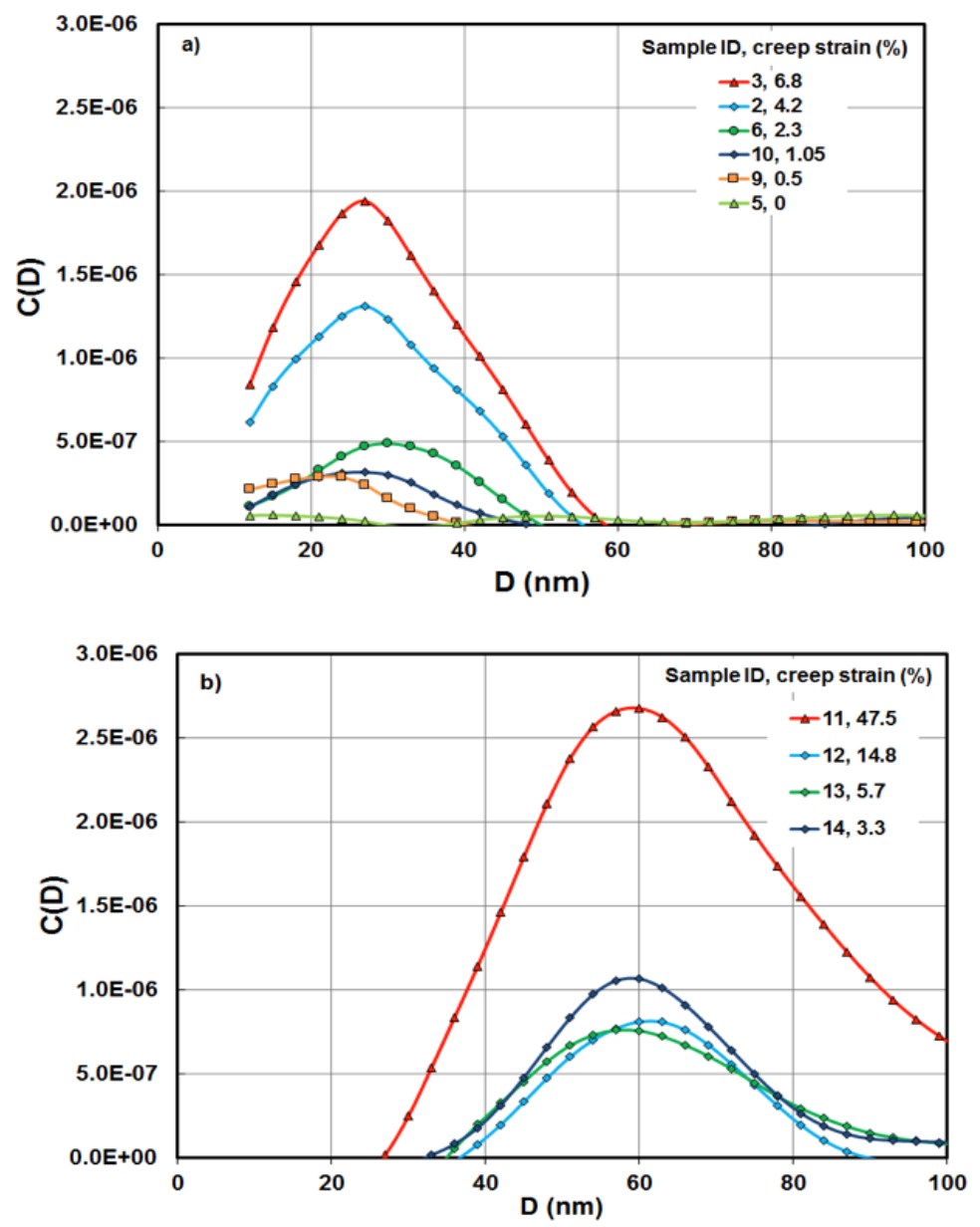

Figure 9. The increase in the fractional size distribution, $C(D)$, of cavities through creep life, determined from SANS, from samples d1 and d5. (a) Due to an applied stress difference of $178 \mathrm{MPa}$ at $550{ }^{\circ} \mathrm{C}$; and (b) an applied stress difference of $83 \mathrm{MPa}$ at $675{ }^{\circ} \mathrm{C}$.

\subsection{Quantitative Metallography}

A typical cavitated microstructure, for specimen HRA1C under the creep condition of $550{ }^{\circ} \mathrm{C}$ and an applied stress of $320 \mathrm{MPa}$, and at creep strain of $6.77 \%$, is shown in Figure 10. Cavities (A) are mainly surrounding intergranular precipitates (B), and intragranular precipitates $(\mathrm{C})$ are seen as dark spots. A recent study on $316 \mathrm{H}$ austenitic stainless steel has shown that both the intergranular and intragranular precipitates are mainly $\mathrm{M}_{23} \mathrm{C}_{6}$ carbides; however, the intragranular precipitates are associated with a long service history, and they form at later stages of creep [15]. Intergranular precipitates do not explicitly lead to cavitation at the grain boundaries [33]. It has been shown that the cavities nucleate at intergranular $\mathrm{M}_{23} \mathrm{C}_{6}$ carbides in high residual stress regions [34].

Image analysis was carried, out in order to quantify the variation in the size and area fraction of the creep cavities. For this purpose, sequential backscattered electron images (BSE), acquired by SEM at an accelerating voltage of $10 \mathrm{kV}$ and magnification of $20 \mathrm{k}$, were examined, covering a total area of over $4700 \mathrm{~mm}^{2}$. The BSE images were analyzed using ImageJ software (ImageJ1.x, National Institute of Mental Health, Bethesda, Rockville, MD, USA) [35]. As previously reported [17], by defining an appropriate contrast threshold, it is possible to separate the creep cavities from the surrounding carbides shown in Figure 10. Cavities can be separated from fine intragranular carbides according to 
their shape differences, using a circularity factor $\left[4 \pi(\right.$ area $\left.) /(\text { perimeter })^{2}\right]$. This is equal to 1 for perfectly circular precipitates. Cavities were separated from intragranular carbides using a circularity factor of 0 to 0.7 . To make a direct comparison between the mean sizes of the cavities measured by quantitative metallurgy and SANS, cavities up to a $300 \mathrm{~nm}$ diameter of cross- sectional area of $0.071 \mu \mathrm{m}^{2}$, were quantified by QM. The data were separated for the two populations of cavities identified by SANS. Cavities with a cross-sectional area of less than $0.0078 \mu \mathrm{m}^{2}$, corresponding to a diameter of $100 \mathrm{~nm}$, were quantified separately from those having cross-sectional areas between 0.0078 and $0.071 \mu \mathrm{m}^{2}$, corresponding to diameters of between 100 and $300 \mathrm{~nm}$. The percentage area fraction of the cavity population less than $100 \mathrm{~nm}$ in size, measured by QM, is shown in Figure 11. It is seen that the area fraction increases through creep life for both of the test conditions, but the area fraction is higher for $675^{\circ} \mathrm{C}$ and $150 \mathrm{MPa}$ than that which measured for $550^{\circ} \mathrm{C}$ and $320 \mathrm{MPa}$. The same trends are seen in the volumetric SANS data for cavities of less than $100 \mathrm{~nm}$ in size; see Figure 4a,b.

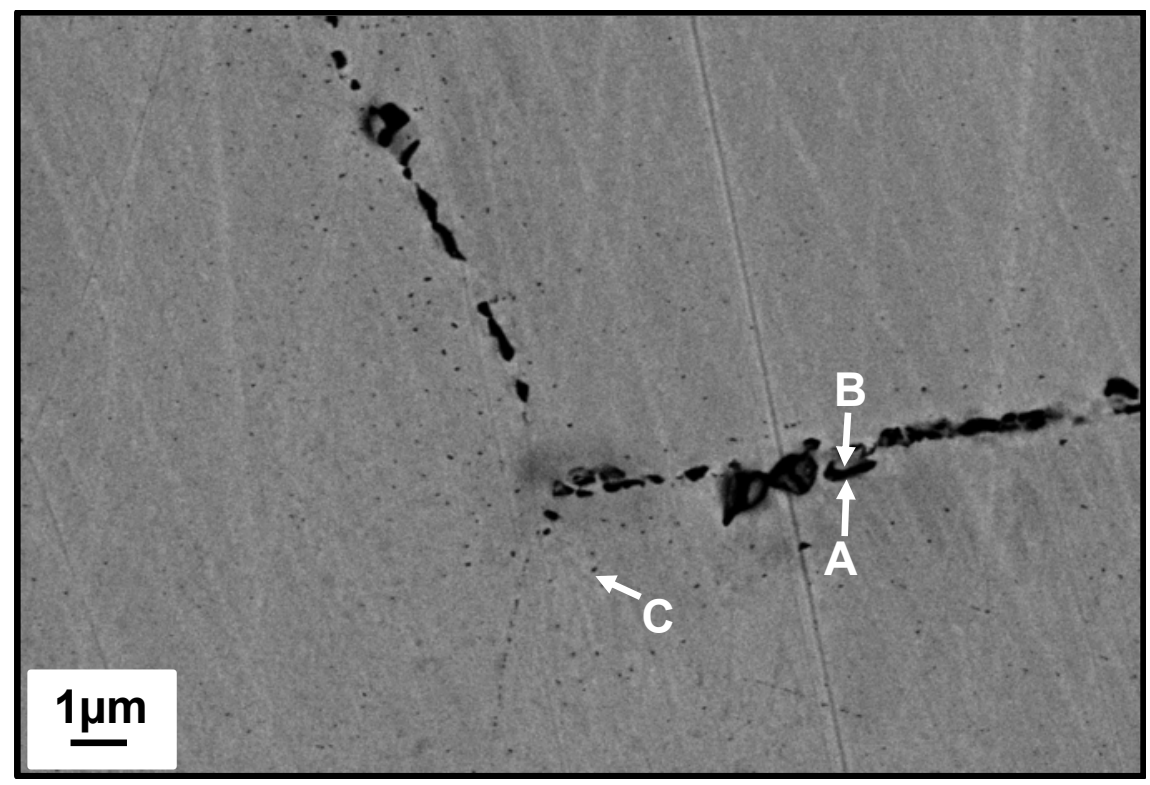

Figure 10. Backscatter image showing the microstructure of a gauge area of the sample 3-d1 under conditions of $550{ }^{\circ} \mathrm{C}$, with an applied stress of $320 \mathrm{MPa}$ (after $8 \%$ pre-strain). Cavities (A) are mainly surrounding intergranular carbides (B). A population of fine intragranular carbides (C) can also be seen, appearing as dark spots adjacent to the grain boundaries.

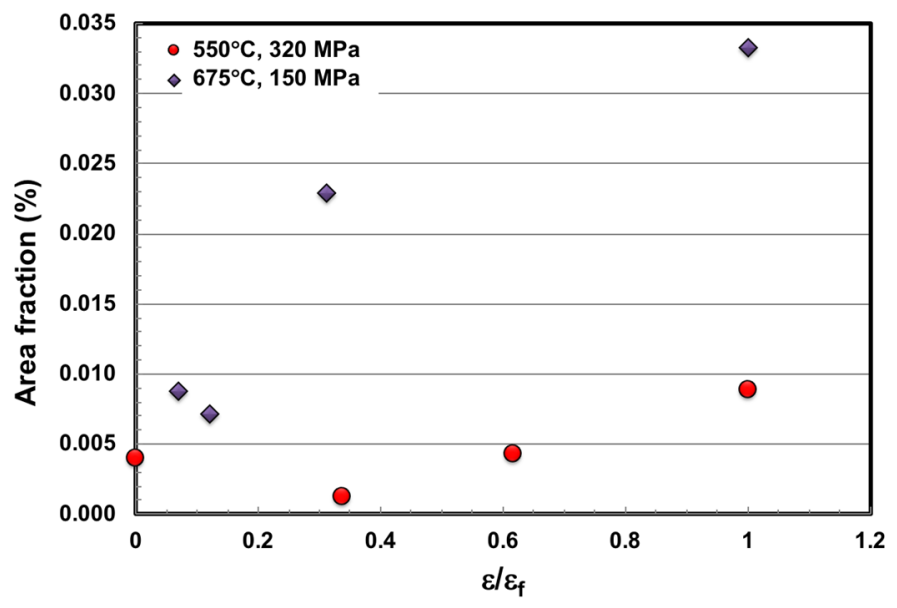

Figure 11. The variation in the area fraction (\%) of cavities less than $100 \mathrm{~nm}$ diameter in size, through creep life, measured by quantitative metallography. 
The mean cavity size associated with the two cavity populations, measured under both creep conditions by SANS and QM techniques is presented in Figure 12. It should be noted that the QM result is based on measuring cavities in a relatively small area $\left(4700 \mu \mathrm{m}^{2}\right)$ compared to that in SANS, which is covering a gauge volume of $9 \mathrm{~mm}^{3}\left(9 \times 10^{9} \mu \mathrm{m}^{3}\right)$. More statistically, valid QM data can only be acquired by automating the SEM imaging in order to cover a larger area. Also, in this study, the smallest cavity quantified by QM had an area of $0.0002 \mu \mathrm{m}^{2}$, or a diameter of $16 \mathrm{~nm}$. Therefore, cavities smaller than $16 \mathrm{~nm}$ in size were not measured by QM. This might have skewed the data and resulted some discrepancy in comparing the measurements, corresponding to the largest $D$. Nevertheless, a good agreement between cavity sizes measured by the two techniques is evident.

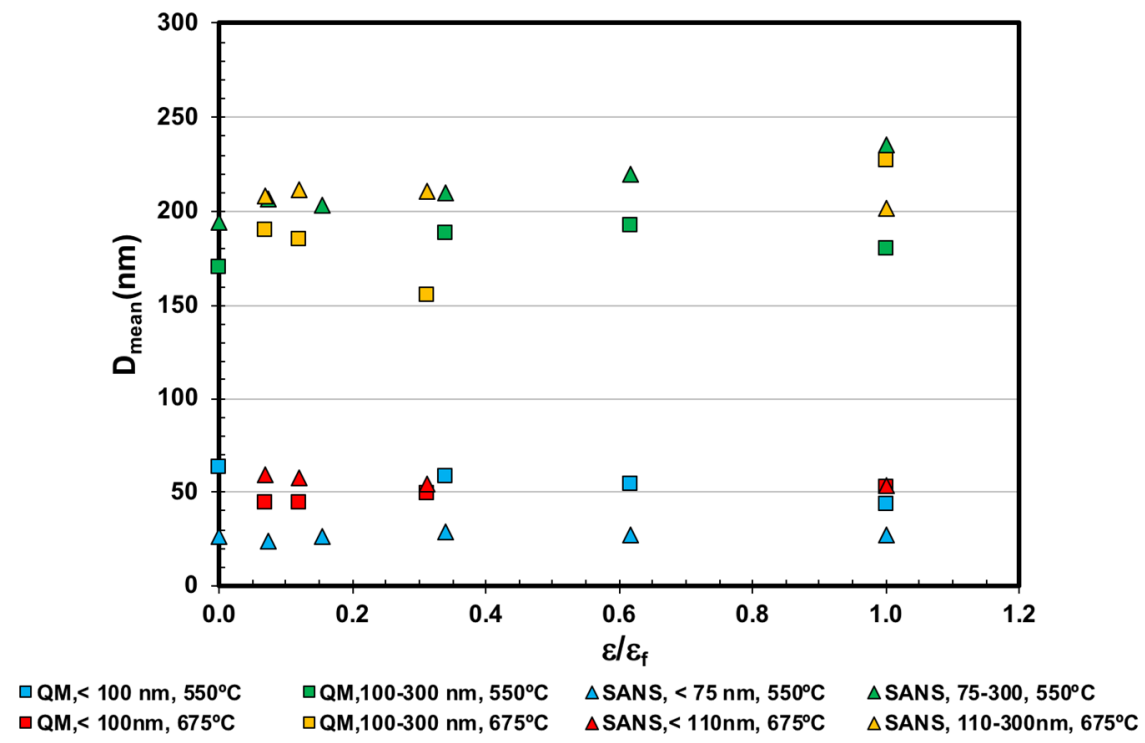

Figure 12. The mean sizes of two populations of cavities, measured by QM and SANS, for creep conditions of $550{ }^{\circ} \mathrm{C}, 320 \mathrm{MPa}$ (after $8 \%$ pre-strain); and $675^{\circ} \mathrm{C}, 150 \mathrm{MPa}$.

\section{Discussion}

The mean diameter of the population of smaller cavities observed from SANS for the tests at $550{ }^{\circ} \mathrm{C}$ under $320 \mathrm{MPa}$ was found to be $39 \mathrm{~nm}$, with a standard deviation of 16.4, and that for the tests at $675{ }^{\circ} \mathrm{C}$ under $150 \mathrm{MPa}$ was found to be $63 \mathrm{~nm}$, with a standard deviation of 30.2. Theoretically, the minimum stable cavity radius in steel is given by $2 \gamma / \sigma$, where $\gamma$ is the surface tension and $\sigma$ is the applied direct stress. For an applied stress of $320 \mathrm{MPa}$, and a surface tension of $2.41 \mathrm{Nm}^{-1}$ for stainless steel [36], a minimum cavity diameter of $30 \mathrm{~nm}$ is expected. The decrease in surface tension as a result of increasing the temperature from 550 to $675^{\circ} \mathrm{C}$ is negligible [37] and the effect of applied stress on the minimum stable cavity radius is more significant. Therefore, at the lower applied load of $150 \mathrm{MPa}$, larger cavities, about $64 \mathrm{~nm}$ in diameter, are expected to be stable. These values are in reasonable agreement with the mean sizes of the small cavities, as measured by SANS.

The large difference in the mean diameters of the creep cavities observed between the two sets of specimens could possibly be attributed to the difference in cavity nucleation mechanisms under the different loading conditions. In the specimens tested at $550{ }^{\circ} \mathrm{C}$ and $320 \mathrm{MPa}$, cavity nucleation might be promoted from the initial plastic pre-straining from the coalescing of piled-up dislocations along a slip plane or against a hard particle. The plastic pre-straining may therefore result in grain boundary void development at the start of the creep test. In Figure $4 a$, a small but noticeable volume fraction of cavities can be observed for sample 5-d1 with $0 \%$ creep strain. Early void nucleation driven by plastic pre-strain may therefore control cavity development mechanisms in this set of samples. Whereas, in the specimens tested at $675^{\circ} \mathrm{C}$ and $150 \mathrm{MPa}$, the nucleation could be promoted by vacancy accumulation. 
A significant increase in the number density of smaller cavities during creep life was observed in the samples tested at $550{ }^{\circ} \mathrm{C}$ and $320 \mathrm{MPa}$, whereas that for the samples tested at $675{ }^{\circ} \mathrm{C}$ and $150 \mathrm{MPa}$ showed little change (see Figure 7). This suggests that the growth mechanisms of the creep cavities during creep life are also different under these two test conditions. At $550{ }^{\circ} \mathrm{C}$ and $320 \mathrm{MPa}$ cavity nucleation continues to occur during creep life, whereas at $675^{\circ} \mathrm{C}$ and $150 \mathrm{MPa}$, cavity initiation and growth both play a key role. The growth of smaller cavities is seen as a shift to a larger size in the peak position of the distribution shown in Figure $4 \mathrm{~b}$, and a small increase in the mean size shown in Figure $6 \mathrm{~b}$.

Dyson [38] showed that tensile creep specimens that were pre-strained at room temperature appeared to have a predisposition for creep cavitation. He also experimentally showed a direct correlation between increasing the pre-strain and creep cavity density. In Figure 7, it can be observed that although the number density of the smaller cavities in the pre-strained specimen increased significantly over the creep life, which for the larger cavities did not. This suggests that although pre-strain promotes cavity nucleation, it does not necessarily affect the cavity growth rate, as previously reported [39]. However, the limitation of the SANS technique in measuring cavities of only up to $300 \mathrm{~nm}$ size must be mentioned here, as the measurement of much larger size cavities may prove otherwise. Finally, the increase in cavity density due to plastic pre-compression reduces the uniaxial creep ductility of the samples. A reciprocal relation of the creep ductility with the rate of cavity production with strain in type 347 stainless steel was reported previously [38]. It can be observed in Figure 7 that the rate of increase in the cavity number density, in particular for smaller sized cavities, with strain in the pre-strained specimens is much higher than those deformed under pure creep at higher temperature. This may explain the much lower creep ductility for the former.

In this work, a systematic increase in the fractional size distribution of cavities formed under increasing creep strain has been found in disc samples cut from creep test specimens having undergone two sets of creep conditions. A previous study using SANS, of a section of a cracked weldment taken from the same component as the specimens examined in this work, has shown a similar increase in the fractional size distribution of cavities at positions approaching the crack along lines normal to the crack line, and along lines parallel to the crack line approaching the crack mouth [32].

By measurements of disc samples from different locations of the test specimen having different diameters, the increase in creep-induced cavity size distribution with applied stress for the two sets of specimens has been determined unambiguously, without the need for a reference sample. This is the case for the pre-strained specimen tested at $550{ }^{\circ} \mathrm{C}$ with a stress difference of $178 \mathrm{MPa}$, and that tested at $675{ }^{\circ} \mathrm{C}$ with a stress difference of $83 \mathrm{MPa}$, except for the highest creep strain of the latter.

The present work shows how SANS can be employed to characterize the volumetric size distributions of creep-induced cavities in uniaxial test samples, and how measurements on sets of interrupted tests can be used to track the evolution of cavities during creep life. In particular, the observations suggest that plastic pre-strain promotes early cavity nucleation. This is significant, because most laboratory creep deformation tests on Type $316 \mathrm{H}$ stainless steel are undertaken by using applied stresses that are greater than the material yield stress, in order to complete the tests within a practical timescale. Thus, creep deformation and damage models based on conventional uniaxial tests innately conflate plastic strain and creep mechanisms. Future work is required to quantify the role of plastic pre-strain on physics and mechanics of cavity nucleation and growth, in order to improve published models, and to develop more realistic lifetime assessment methods for high-temperature power plant applications.

\section{Conclusions}

Small-angle neutron scattering and quantitative metallography are complementary techniques that have been effectively applied to measure creep cavitation up to $300 \mathrm{~nm}$ in size, in two sets of $316 \mathrm{H}$ austenitic stainless steel specimens tested up to rupture at $550{ }^{\circ} \mathrm{C}$ and $320 \mathrm{MPa}$, and at $675{ }^{\circ} \mathrm{C}$ and $150 \mathrm{MPa}$. The former set specimens had been subjected to a plastic pre-strain of $8 \%$. Two populations of 
cavities were observed to develop during creep life: a population of smaller cavities under $\sim 100 \mathrm{~nm}$ in size, and a population of larger cavities $\sim 100-300 \mathrm{~nm}$ in size. For both test conditions, the volume fraction distribution of smaller cavities exhibited a pronounced increase with increasing creep strain; therefore, a continuous nucleation of creep cavitation has been observed throughout those creep lives, for both the pre-strained and purely creep deformed samples. A significant increase in the number density of smaller cavities, less than $100 \mathrm{~nm}$ in size, was observed to develop during creep life in samples that were tested at $550{ }^{\circ} \mathrm{C}$ and $320 \mathrm{MPa}$. However, samples tested at $675{ }^{\circ} \mathrm{C}$ and $150 \mathrm{MPa}$ showed little change in the number density of smaller cavities during creep life, which suggests that cavity growth is the dominant mechanism of creep cavity development under these conditions. In the plastic pre-strained set of specimens, the number density of only the smaller sized cavities was observed to increase with creep life fraction, while that of the larger sized cavities were almost unchanged. This suggests that plastic pre-straining acts as a predisposition for creep cavity nucleation in this material. Future work is required to quantify the role of plastic pre-strain on physics and mechanics of cavity nucleation and growth, in order to improve published models, and to develop more realistic lifetime assessment methods for high-temperature power plant applications.

Author Contributions: Data curation: H.J.; M.T.H.; A.A.M. and R.K.H.; Formal analysis: H.J.; M.T.H.; and A.A.M.; Funding acquisition: P.J.B. and H.J.; Investigation: H.J.; M.T.H. and A.A.M.; Methodology: H.J. and M.T.H.; Supervision: P.J.B.; Validation: H.J.; M.T.H. and M.W.S. Writing-Original Draft, H.J. and Writing-Review \& Editing, H.J.; P.J.B.; M.T.H.; A.A.M. and M.W.S.

Acknowledgments: This research was funded by EDF Energy, grant number 4840543478 . The APC was funded by the Science, Technology, Engineering, and Mathematics (STEM) faculty at The Open University. The help of Sarah Rogers is acknowledged in undertaking the SANS experiments.

Conflicts of Interest: The authors declare no conflict of interest.

\section{References}

1. Kassner, M.E.; Hayes, T.A. Creep cavitation in metals. Int. J. Plast. 2003, 19, 1715-1748. [CrossRef]

2. Greenwood, J.N. Intercrystalline cracking of metals. J. Iron Steel Inst. 1954, 176, 268-269.

3. Greenwood, J.N.; Miller, D.R.; Suiter, J.W. Intergranular cavitation in stressed metals. Acta Metall. 1954, 2, 250-258. [CrossRef]

4. Chen, B.; Flewitt, P.E.J.; Smith, D.J.; Jones, C.P. An improved method to identify grain boundary creep cavitation in 316H austenitic stainless steel. Ultramicroscopy 2011, 111, 309-313. [CrossRef] [PubMed]

5. Kassner, M.E. Fundamentals of Creep in Metals and Alloys; Elsevier Science: Amsterdam, The Netherlands, 2008; pp. 225-226. [CrossRef]

6. Chen, R.T.; Weertman, J.R. Grain boundary cavitation in internally oxidized copper. Mater. Sci. Eng. 1984, 64, 15-25. [CrossRef]

7. Chen, I.W.; Argon, A.S. Creep cavitation in 304 stainless steel. Acta Metall. 1981, 29, 1321-1333. [CrossRef]

8. Riedel, H. Cavity nucleation at particles on sliding grain boundaries. A shear crack model for grain boundary sliding in creeping polycrystals. Acta Metall. 1984, 32, 313-321. [CrossRef]

9. Boettner, R.C.; Robertson, W.D. A study of the growth of voids in copper during the creep process by measurement of the accompanying change in density. Trans. Met. Soc. 1961, 221, 613-622.

10. Evans, H.E. Mechanisms of Creep Fracture; Elsevier Applied Science Publishers Ltd.: London, UK, 1984.

11. Nix, W.D. Introduction to the viewpoint set on creep cavitation. Scr. Metall. 1983, 17, 1-4. [CrossRef]

12. Sandström, R.; He, J. Grain boundary sliding. In Survey of Creep Cavitation in fcc Metals; IntechOpen: London, UK, 2017. [CrossRef]

13. He, J.; Sandström, R. Formation of creep cavities in austenitic stainless steels. J. Mater. Sci. 2016, 51, $6674-6685$. [CrossRef]

14. Bouchard, P.J.; Withers, P.J.; McDonald, S.A.; Heenan, R.K. Quantification of creep cavitation damage around a crack in a stainless steel pressure vessel. Acta Mater. 2004, 52, 23-34. [CrossRef] 
15. Burnett, T.L.; Geurts, R.; Jazaeri, H.; Northover, S.M.; McDonald, S.A.; Haigh, S.J.; Bouchard, P.J.; Withers, P.J. Multiscale 3D analysis of creep cavities in AISI type 316 stainless steel. Mater. Sci. Technol. 2015, 31, 522-534. [CrossRef]

16. Dyson, B.F.; Loveday, M.S.; Rodgers, M.J. Grain boundary cavitation under various states of applied stress. Proc. R. Soc. Lond. A 1976, 349, 245-259. [CrossRef]

17. Jazaeri, H.; Bouchard, P.J.; Hutchings, M.T.; Lindner, P. Study of creep cavitation in stainless steel weldment. Mater. Sci. Technol. 2014, 30, 38-42. [CrossRef]

18. Jazaeri, H.; Bouchard, P.J.; Hutchings, M.T.; Lindner, P. Study of creep cavitation in a stainless steel weldment using small angle neutron scattering and scanning electron microscopy. In Proceedings of the ASME 2014 Pressure Vessels \& Piping Conference, Materials and Fabrication, PVP2014-28641, Anaheim, CA, USA, 20-24 July 2014. [CrossRef]

19. Rustichelli, F. Applications of small neutron scattering in material science and rechnology. Metall. Sci. Technol. 1993, 11, 118-141.

20. Bouchard, P.J.; Fiori, F.; Treimer, W. Characterisation of creep cavitation damage in a stainless steel pressure vessel using small angle neutron scattering. Appl. Phys. A Mater. Sci. Process. 2002, 74, S1689-S1691. [CrossRef]

21. Hales, R. The role of cavity growth mechanisms in determining creep-rupture under multiaxial stresses. Fatigue Fract. Eng. Mater. Struct. 1994, 17, 579-591. [CrossRef]

22. Acar, M.; Gungor, S.; Bouchard, P.J.; Fitzpatrick, M.E. Effect of prior cold work on the mechanical properties of weldments. In Proceedings of the 2010 SEM Annual Conference and Exposition on Experimental and Applied Mechanics, Indianapolis, IN, USA, 7-10 June 2010; Volume 6, pp. 817-826.

23. Wilshire, B.; Willis, M. Mechanisms of strain accumulation and damage development during creep of prestrained 316 stainless steels. Metall. Mater. Trans. A 2004, 35, 563-571. [CrossRef]

24. Githinji, D.N. Characterisation of Plastic and Creep Strains from Lattice Orientation Measurements; The Open University: Milton Keynes, UK, 2013.

25. Hong, H.U.; Nam, S.W. The occurrence of grain boundary serration and its effect on the M23C6 carbide characteristics in an AISI 316 stainless steel. Mater. Sci. Eng. A 2002, 332, 255-261. [CrossRef]

26. Heenan, R.K.; Rogers, S.E.; Turner, D.; Terry, A.E.; Treadgold, J.; King, S.M. Small angle neutron scattering using Sans2d. Neutron News 2011, 22, 19-21. [CrossRef]

27. Akeroyd, F.; Ansell, S.; Antony, S.; Arnold, O.; Bekasovs, A.; Bilheux, J.; Borreguero, J.; Brown, K.; Buts, A.; Campbell, S.; et al. Mantid: Manipulation and Analysis Toolkit for Instrument Data. Available online: http:/ / dx.doi.org/10.5286/SOFTWARE/MANTID (accessed on 31 December 2013).

28. Heenan, R.K.; Penfold, J.; King, S.M. SANS at pulsed neutron sources: present and future prospects. J. Appl. Cryst. 1997, 30, 1140-1147. [CrossRef]

29. Hutchings, M.T.; Windsor, C.G. 25. Industrial Applications. In Methods in Experimental Physics; Sköld, K., Price, D.L., Eds.; Academic Press: Cambridge, MA, USA, 1987; Volume 23, pp. 405-482. [CrossRef]

30. Potton, J.A.; Daniell, G.J.; Rainford, B.D. A new method for the determination of particle size distribution from Small-Angle Neutron Scattering Measurements. J. Appl. Cryst. 1988, 21, 891-897. [CrossRef]

31. Hutchings, M.T. The Use of Small Angle Neutron Scattering for Mapping Creep Cavitation Damage in an Ex-Service Steam Header; The Open University: Milton Keynes, UK, 2012.

32. Jazaeri, H.; Bouchard, P.J.; Hutchings, M.T.; Mamun, A.A.; Heenan, R.K. Application of small angle neutron scattering to study creep cavitation in stainless steel weldments. Mater. Sci. Technol. 2015, 31, 535-539. [CrossRef]

33. Slater, T.J.A.; Bradley, R.S.; Bertali, G.; Geurts, R.; Northover, S.M.; Burke, M.G.; Haigh, S.J.; Burnett, T.L.; Withers, P.J. Multiscale correlative tomography: an investigation of creep cavitation in 316 stainless steel. Sci. Rep. 2017, 7, 7332. [CrossRef] [PubMed]

34. Pommier, H.; Busso, E.P.; Morgeneyer, T.F.; Pineau, A. Intergranular damage during stress relaxation in AISI 316L-type austenitic stainless steels: Effect of carbon, nitrogen and phosphorus contents. Acta Mater. 2016, 103, 893-908. [CrossRef] 
35. Rasband, W.S. ImageJ1.x; U.S. National Institutes of Health: Bethesda, MD, USA. Available online: https:/ / imagej.nih.gov/ij/ (accessed on 31 December 2013).

36. Yu, J.; Lin, X.; Wang, J.; Chen, J.; Huang, W. First-principles study of the relaxation and energy of bcc-Fe, fcc-Fe and AISI-304 stainless steel surfaces. Appl. Surf. Sci. 2009, 255, 9032-9039. [CrossRef]

37. Kristyan, S.; Giber, J. Temperature dependence of the surface free energies of solid chemical elements. Surf. Sci. 1988, 201, L532-L538. [CrossRef]

38. Dyson, B.F. Continuous cavity nucleation and creep fracture. Scr. Metall. 1983, 17, 31-37. [CrossRef]

39. Dyson, B.F.; Rodgers, M.J. Prestrain, cavitation, and creep ductility. Met. Sci. 1974, 8, 261-266. [CrossRef]

(C) 2019 by the authors. Licensee MDPI, Basel, Switzerland. This article is an open access article distributed under the terms and conditions of the Creative Commons Attribution (CC BY) license (http:/ / creativecommons.org/licenses/by/4.0/). 